NBER WORKING PAPER SERIES

\title{
RETIREMENT EFFECTS OF PROPOSALS BY THE PRESIDENT'S COMMISSION TO STRENGTHEN SOCIAL SECURITY
}

\author{
Alan L. Gustman \\ Thomas L. Steinmeier \\ Working Paper 10030 \\ http://www.nber.org/papers/w10030
}

\author{
NATIONAL BUREAU OF ECONOMIC RESEARCH \\ 1050 Massachusetts Avenue \\ Cambridge, MA 02138 \\ October 2003
}

Analyses of the effects of Social Security policies were supported by a grant from the U.S. Social Security Administration (SSA) to the Michigan Retirement Research Center, with a subcontract to the National Bureau of Economic Research. Estimation of the model on which these simulations are based was also supported by a grant from the National Institute on Aging (1R01AG13913-01A1) to NBER. We would like to thank Stephen Goss for his very helpful comments. The opinions and conclusions are solely those of the authors and should not be construed as representing the opinions or policy of SSA, NIA or any other agency of the Federal Government, the Michigan Retirement Research Center, or the National Bureau of Economic Research. Alan L. Gustman is Loren Berry Professor of Economics at Dartmouth College, Department of Economics, Hanover, N.H. 03755 (alan.1.gustman@dartmouth.edu). Thomas L. Steinmeier is Professor of Economics, Texas Tech University, Department of Economics, Lubbock, Texas 79409 (Thomas.Steinmeier@TTU.edu).

C2003 by Alan L. Gustman and Thomas L. Steinmeier. All rights reserved. Short sections of text, not to exceed two paragraphs, may be quoted without explicit permission provided that full credit, including (C) notice, is given to the source. 
Retirement Effects of Proposals by the President's Commission to Strengthen Social Security Alan L. Gustman and Thomas L. Steinmeier

NBER Working Paper No. 10030

October 2003

JEL No. H55, J26, J14, J32, E21, D31, D91, I3

\begin{abstract}
A structural dynamic model of retirement and saving is used to simulate the retirement effects of proposals made by the President's Commission to Strengthen Social Security. Provisions reducing the growth in real benefits and increasing actuarial incentives to work reduce retirements. They more than offset increases in retirements caused by individual accounts, increased benefits for low wage workers and survivors, and reductions in the top AIME bracket. By 2075, the Commission's proposals would reduce retirements at age 62 by roughly 4 percentage points, mitigating an 8.7 percentage point trend to earlier retirement projected to reassert itself after its recent interruption.
\end{abstract}

\author{
Alan L. Gustman \\ Department of Economics \\ Dartmouth College \\ Hanover, NH 03755 \\ and NBER \\ alan.1.gustman@dartmouth.edu
}

Thomas L. Steinmeier

Department of Economics

Texas Tech University

Lubbock, TX 79409

thomas.steinmeier@ttu.edu 


\section{Introduction}

In December 2001, the President’s Commission to Strengthen Social Security (CSSS) issued its final report. Rather than a single reform model to modify social security, the Commission explored three different reform models, all of which include the introduction of voluntary personal accounts. In addition, the proposals would reduce the rate of growth of real benefits, introduce actuarial incentives to encourage later retirements, increase benefits for low wage workers and survivors, and reduce the top AIME bracket.

The specific elements of social security that the Commission would change would also be changed by other proposals to reform social security so as to rebalance its finances. Thus an analysis of the retirement effects of the elements comprising the Commission's proposal are of more general interest than the specific models the Commission proposed. The effects we estimate here for each specific change can be used to estimate the likely effects on retirement of other proposals that would weight these changes differently than the President's Commission did in structuring its various reform proposals.

The first reform model introduced by the Commission does nothing to address the longterm funding imbalances in the social security system. The second and third proposals do include elements to strengthen the system, and as a result these are the proposals that are being given the most consideration.

In many ways the Commission reform models are constrained by the specific principles given to the Commission by the President. Most importantly, the reform models are required to include personal retirement accounts, and these must be voluntary. To make the personal accounts attractive to the entire range of covered workers, including those who are effectively 
receiving transfers under the current system, the Commission devised an offset system. For every dollar of payroll taxes diverted to the personal account, future traditional benefits will be reduced by a specified present value amount. To mitigate the solvency problem, traditional benefits are prescribed to grow more slowly than would be the case under the current formula. Since the current formula maintains a roughly constant replacement rate as overall earnings increase over time, this method implies that social security will become a less important element in the retirement resources equation.

In these proposals, the Commission also included several elements in addition to the personal accounts. Some of these proposals would increase the relative benefits paid to lowwage workers and their widows, and others would reduce the relative benefits of higher income workers. In one reform model, the Commission also included changes to try to induce individuals to retire later, further reducing early retirement benefits and raising the delayed retirement credit.

The Actuaries' Supplement appended to the Commission report traces the effects of the reform models on the financial health of the system and on the income levels of various groups of individuals who would be affected by the changes. However, several of the elements of these reform models can be expected to have non-trivial effects on retirement. These retirement effects are not considered in the Actuaries' Supplement or, as far as we are aware, in any other analysis of the Commission proposals.

To simulate the retirement effects of the various elements of the Commission proposals, we use a structural dynamic model of retirement and saving that we have developed for previous work. This model posits lifetime expected utility that is constrained by an asset accumulation 
equation and an uncertain lifetime. Retirement preferences and time preferences are both allowed to be heterogeneous among workers. Workers are allowed to partially retire, usually in a different job at a lower wage rate. Social security enters as income in the asset accumulation equation in the years that benefits are received. The current utility value of the future benefits is, of course, heavily dependent on the worker's time preference rate. We apply the model to simulate the retirement effects of the Commission proposals on a sample of married men.

In the next section, we detail more fully the aspects of the Commission proposals that we intend to evaluate. The following section contains a brief discussion of prior efforts to model savings and retirement. Section IV explains the model we use in the analysis and the method we use to estimate it. A description of the simulation methodology appears in the following section. In Section VI, we present the results of the simulations of the effects of elements of the Commission's proposals on retirement. A final section offers concluding remarks.

\section{The CSSS Proposals}

Personal accounts are the most prominent element of the Commission proposals. The accounts themselves are fairly standard, but the offset to traditional benefits is not. For each dollar that the individual diverts into the personal account, a dollar is placed into a fictitious “offset” account. ${ }^{1}$ The balance in this notional offset account is compounded at a fixed real interest rate until the individual is ready to collect benefits. At that time, the balance in the offset account is annuitized, and the resulting amount is subtracted from the annual benefits that the

\footnotetext{
${ }^{1}$ Gustman and Steinmeier (2002a) show that in computing the eventual retirement benefit, the proposal both adds and subtracts the principal in the account. As a result the individual's benefit under the proposal is equal to the basic benefit under the relevant social security benefit formula plus the annuitized value of any differential interest rate earnings or losses on the personal account.
} 
individual would receive under the traditional social security system. In the second Commission reform model, the real interest rate used in the offset account is $2.0 \%$, while in the third reform model it is $2.5 \%$. Both are lower than the $3.0 \%$ long-term projected real rate for treasury bonds. If the assets in the personal accounts grow by more than the assumed offset rate, the individual increases wealth by participation in the personal account; if not he or she loses. Since the offset rate is lower than the rate for relatively safe treasury bonds, and since on average the varying market rates will have decades to even themselves out, and will likely exceed the offset rates, the expectation is that in most cases the individual would be ahead to participate in the personal accounts.

The retirement effects of the personal accounts depend to some degree on how the payout of the accounts is arranged. The commission's report suggests that the withdrawals from the accounts should begin after an individual retires, but "retirement" is a somewhat ambiguous term. Does it mean when the individual ceases working, or when he earns less than some minimal amount? Or does it mean when the individual works less than some number of hours in a year? The retirement effects of the personal accounts also depend on the realizations of the returns to those accounts. If the returns to the accounts substantially exceed expectations, individuals might want to retire earlier, while if the accounts perform poorly individuals might want to delay retirement. In this regard the retirement effects of the personal accounts are very similar to the effects of holding risky assets in non-social security retirement accounts, an issue we examined very recently in the context of the 1995-2002 stock market bubble (Gustman and Steinmeier, 2002c). Given the findings of that study, in conjunction with the relatively small size of the personal social security accounts, it would appear that even a major swing in stock 
prices would probably cause no more than a percent or so change in the percentage of retired individuals because of the personal accounts.

In this paper, we will consider the retirement effects of the personal accounts as well as the remainder of the measures in the Commission's reform models. Table 1 summarizes these measures for the second and third of the Commission's reform models. As is evident from the table, the two reform models share some common features in addition to the personal accounts, but there are also some important differences. In addition, the third reform model contains a couple of features that are absent from the second reform model.

In terms of restoring the financial balance to social security, the second element listed in the table is by far the most important. In reform model 2, the percentages in the PIA formula would be adjusted downward every year so that the average benefit would remain roughly constant in real terms. In reform model 3 , the adjustments would hold the growth in the average benefits to the growth in earnings less the growth in average life expectancy. In practical terms, this means that the average real benefits in reform model 3 would grow at about 0.5 percent per year, as opposed to a projected real earnings growth of 1 percent per year. In either case, the replacement rate of social security benefits to earnings would be gradually reduced below levels called for in the current formula, and the influences of social security on retirement would be gradually reduced. The effect should be about twice as great with reform model 2 as with reform model 3. In reform model 2, the size of traditional social security benefits, relative to wages, would be less than half as much at the end of the 75 year planning period as they are today. Both reform models also have provisions to maintain the benefits of long-term low-wage workers at or above the poverty level, although the details differ. Reform model 2 would boost 
the basic benefit of a 30 year minimum wage worker by about $40 \%$, which is enough to provide benefits at roughly 120 percent of the poverty level. This boost would be proportionately reduced toward zero for workers with less than 20 years of experience and for workers with lifetime earnings exceeding the earnings of a 35 year worker with twice the minimum wage. Reform model 3 would give the 30 year minimum wage worker a smaller boost of 12 percent, but the boost would extend all the way up to the average wage level before it is phased out. It would also be phased out for individuals with less than 20 years of covered earnings, but additional years of earnings beyond 30 would result in an even higher boost, which contrasts with the case of reform model 2. Overall, one would expect that the boosts for low wage workers in reform model 2 would be greater, but would cover a smaller percent of the work force.

Reform model 3 contains a proposal to impose a larger reduction in benefits for retiring early and to raise benefits more when retirement is delayed, so as to improve incentives to work longer. It is the only part of any of the proposals whose primary purpose is explicitly to increase the age at which people retire. Under current law, when the normal retirement age increases to age 67, retirees at age 62 will receive 70 percent of full benefits, while delaying retirement past age 67 will increase benefits by 8 percent per year. Under the proposal, age 62 retirees would receive only 63 percent of full benefits, while delaying retirement past age 67 would increase benefits by 10 percent per year of delay. Similar changes for spouse benefits would make the benefits payable at age 62 only 58 percent of full benefits as opposed to 65 percent under the current law.

A fourth element of the Commission proposals, which is essentially the same for both 
reform models, is to increase the surviving spouse benefit of low-wage couples to $75 \%$ of the benefit that would have been received if both spouses were still living. This provision applies if the surviving spouse benefit is less than the average benefit for retired workers. ${ }^{2}$ Currently the surviving spouse benefit is between $50 \%$ and $67 \%$ of the couple's combined benefit, so the change would raise the benefits of eligible surviving spouses by between 13 and 50 percent, which is a nontrivial magnitude. On the other hand, at the time retirement decisions are made, the applicability of surviving spouse benefits is probably a couple of decades away, and this extended length of time will tend to dull the effect of this provision on retirement.

The last element listed in the table, which again applies only to reform model 3, is a proposal to drop the percentage rate in the highest PIA bracket from 15 percent to 10 percent. The reduction in benefits for high wage workers is much less than the one third decline in this percentage would suggest. Even for individuals with relatively high average earnings, most of the social security benefit comes from the first two brackets of the PIA formula, which replace 90 percent and 32 percent of average earnings, respectively. The clear intent of this proposal is to generate some of the funds necessary to finance some of the additional subsidy given to lowwage workers, thus offsetting the negative effects of some of the other proposed changes on the bottom part of the distribution.

The reform models have some other elements related more to the financing issue rather than to the retirement issue. Notably, both reform models 2 and 3 call for the infusion of funds

${ }^{2}$ In addition to its effect on the primary earner, this provision will reduce work incentives for low wage spouses. We do not model the work behavior of spouses in this paper. For an analysis that takes into account interdependence in the retirement decision making of husbands and wives using the HRS, see Gustman and Steinmeier (forthcoming). 
from the general treasury for at least some periods. It would be necessary to consider these elements if the purpose of the paper were to examine the relative effectiveness of the reform models to solve the solvency issue, but it is probably less critical to examine them in an analysis of the effects of these reform models on retirement. As a result, we will limit the analyses in this paper to the proposals listed in Table 1, which are the main proposals that can be expected to have a significant impact on retirement.

\section{Issues in Modeling the Retirement Effects of Changing Social Security Policies}

There is a long tradition in modeling the effects of social security policies on retirement. Many studies use panel data to estimate models based on a life cycle approach. ${ }^{3}$ Most of these models can explain behavioral responses to sharp changes in the present value of rewards with continued work. They do a poorer job of explaining responses to provisions such as the social security early retirement age. Since benefits are reduced on an actuarially fair basis between early and normal retirement age, there is no spike in the benefit accrual profile, and no decline in benefit accruals to explain the sharp spike at age 62 in retirements. Thus to explain the peak in retirements at age 62, Coile and Gruber (2002) and Panis et al. (2002) have had to include age dummies, and the coefficient on the dummy for age 62 is strong and significant. Without explaining this important feature of the retirement hazard, one does not have a reliable baseline

${ }^{3}$ Much of the early literature is based on the 1969-79 Retirement History Study. See, for example, Gordon and Blinder (1980), Burtless and Moffitt (1984), Fields and Mitchell (1984), Gustman and Steinmeier $(1985,1986,1991)$ and Rust and Phelan (1997) for contributions to this literature based on the Retirement History Study. For a survey of the retirement literature, see Lumsdaine and Mitchell (1999). 
from which to judge how changes in social security rules will affect retirement outcomes. ${ }^{4}$

Gustman and Steinmeier (2002b) suggest that to explain retirement at age 62, two things

are required. First, it is necessary to relax the assumption of a perfectly operating capital market, which characterizes all but a few structural retirement models. ${ }^{5}$ Second, it is necessary to allow for the sharp heterogeneity in time preference which underlies the saving data, where many have either a very low or a very high time preference rate. Without allowing for this distinction in time preference, which our model estimates from saving data, it is not possible to explain both the peaks in retirements, at ages 62 and 65 . Nor can one explain the failure of some to respond to the enhancements of actuarial incentives in social security such as those we analyze in this paper.

\section{A Structural Model of Retirement and Saving}

The model that we will use to simulate the effects of the Commission plans on retirement and saving has been previously used in Gustman and Steinmeier (2002b) to estimate the effects of raising the social security early entitlement age. Here we will sketch the nature of the model so that readers can gain some idea of the framework of the analysis, but we refer readers back to the earlier paper for a more detailed discussion of the model and its estimation.

The individual is assumed to maximize a utility function of consumption and leisure over

${ }^{4}$ One can use a simple reduced form retirement model to explain the retirement peak at age 62. All one must do is to choose a high discount rate. However, it then is not possible to explain the peak in retirements at age 65. More generally, Gustman and Steinmeier (2000/2001) find that the restrictions implied by a simple life cycle model with single peaked distributions of time and leisure preferences are violated in reduced form estimates of retirement and wealth equations. A more complex version of the life cycle model is required to jointly explain retirement and saving behavior.

${ }^{5}$ For exceptions, see Rust and Phalen (1997) and French (2002). 
time:

$$
\mathrm{U}=\int_{0}^{\mathrm{T}} \mathrm{e}^{-\rho \mathrm{t}} \sum_{\mathrm{m}=0}^{2}\left\{\mathrm{~s}_{\mathrm{m}, \mathrm{t}}\left[\frac{1}{\alpha} \mathrm{C}_{\mathrm{m}, \mathrm{t}}^{\alpha}+\mathrm{h}_{\mathrm{t}} \frac{1}{\gamma} \mathrm{L}_{\mathrm{m}, \mathrm{t}}^{\gamma}\right]\right\} \mathrm{dt}
$$

In this expression, $\mathrm{C}$ is consumption and $\mathrm{L}$ is the utility value of leisure. $\mathrm{t}$ indexes time over the individual's adult life, and $\rho$ is the time preference rate. m indexes three survival states for a married individual: both spouses are alive; only the respondent is alive; or only the spouse is alive. $s_{m, t}$ is the probability that the couple is in the survival state denoted by $\mathrm{m}$ at time $\mathrm{t}$.

The term $h_{t}$, which is the relative value of leisure at time $t$, is given by the expression $h_{t}=e^{X_{t} \beta+\varepsilon}$. In this version of the model, $X_{t}$ contains a constant, an age variable, an indicator of poor health, and the birth year. The age variable presumably has a small positive coefficient which gradually increases the value of leisure over time and reflects the gradual wear and tear which makes the rigors of work relatively less attractive with age. As the value of leisure increases, at some point it surpasses the utility of the consumption that continued work makes possible, and the individual retires. It is important to note that the effects of age are gradual, and that unlike many models of retirement, in this model there are no terms in the preference function which would make retirement suddenly more desirable at specific ages such as 62 or 65 . The parameter $\epsilon$ in the expression for $h_{t}$ varies among individuals and reflects the fact that some individuals give leisure more weight than others. It is presumed to come from a normal distribution with zero mean and standard deviation $\sigma_{\epsilon}$.

Individuals working more than 30 hours per week and more than 1560 hours per year are 
classified as full-time. Those working more than 100 hours per year but less than 25 hours per week are classified as part-time. Individuals who fall between full-time and part-time or between part-time and retired are classified on the basis of self reports.

Leisure takes on a value of 0 for full-time work, 1 for full retirement, and $1 / 2$ for partial retirement. The utility value of leisure $V_{L}=\frac{1}{\gamma} L^{\gamma} \quad$ thus takes on a value of 0 for fulltime work, 1 for full retirement and, for partial retirement, $V_{p}$ (which should take on a value $L_{p}$ between 0.5 and 1 for permissible values of $\gamma$ ). We assume that each individual gets a random draw of $V_{p}$ from the relevant part of the exponential distribution $k e^{\delta V_{p}} \cdot k$ is a constant necessary to normalize the distribution to integrate to unity between 0.5 and $1 .{ }^{6}$ In order to reflect that partial retirement becomes relative more common at older ages, we allow this distribution to shift as the individual ages by specifying that $\delta=\delta_{o}+\delta_{a}$ Age. Thus the entire distribution of the preferences for partial retirement increases over time, although everyone maintains their relative position in the distribution.

These preferences allow for three types of heterogeneity. The time preference parameter $\rho$ is treated as a fixed effect whose value makes the wealth implied by the model consistent with the observable wealth in 1992 for each individual. The other two types of heterogeneity are $\epsilon$, the general preference for leisure, and $V_{p}$, the relative attractiveness of partial retirement. They are treated as random unobserved effects within the model, coming from distributions characterized by $\sigma_{\epsilon}, \delta_{o}$ and $\delta_{a}$.

\footnotetext{
${ }^{6}$ We initially tried a truncated normal distribution, but the relevant part of the distribution always was estimated to be in the tail. As a result, we changed to the exponential distribution in order to minimize the number of parameters being estimated.
} 
This utility function is maximized subject to the asset constraint

$$
A_{t}=(1+r) A_{t-1}+W_{t}\left(1-L_{t}\right)+E_{t}+B_{t}-C_{t} .
$$

In this equation, $A_{t}$ is the level of assets at time $t$, and $r$ is the real interest rate.

The next term $\mathrm{W}_{t}\left(1-\mathrm{L}_{\mathrm{t}}\right)$ is earnings, with the wage rate being either the full-time wage or the partial retirement real wage rate depending on the choice of $\mathrm{L}_{\mathrm{t}} \cdot \mathrm{E}_{\mathrm{t}}$ is the earnings of the spouse, including any pension benefits. $B_{t}$ is the sum of the individual's own pension benefits and family social security benefits, both of which may be influenced by the individual's previous and current work decisions. $\mathrm{C}_{\mathrm{t}}$ is consumption at time t. Note that the pension and social security amounts are actual benefits, not accruals. This means that social security and pension wealth are not explicitly calculated but rather are implicitly determined by the fact that the benefits enter the asset constraint in future periods.

$A_{t}$ starts at zero in the first period, which corresponds to the year the respondent turns age 25 , and is restricted to be non-negative thereafter. Non-negativity of assets prevents individuals with high time preference rates from borrowing against future wages, pensions, and social security and consuming a majority of lifetime resources early in life. Rather, such individuals will in most periods simply consume their available resources and will build up very few assets with which to finance retirement. Individuals with lower time preferences, on the other hand, will soon begin saving and will build up a much greater level of assets by the time they retire.

The model is estimated for a sample of 2305 married men from the Health and Retirement Study using observations for the first five waves of the survey, every other year from 
1992 through 2000. ${ }^{7}$ Potential earnings profiles are taken from social security records or, if these are not available, from the retrospective information in the respondent surveys. Future potential earnings are projected on the basis of tenure and experience coefficients of earnings regressions. Pension benefits, conditional on tenure in the job providing the pension, are based on information in the summary pension descriptions, provided by the employers. Social security benefits are based on the earnings histories and figured according to the social security rules.

The sample is limited to married men for two reasons. First, the Health and Retirement study does not collect much information on former spouses, so it is difficult to estimate the model for divorced or widowed men, who make up the majority of non-married men in the sample. Secondly, it seems risky to group men and women together in the same analysis, given the differences other researchers have found in their retirement behavior. The sample is further reduced for several data problems. The two most important reasons for deletion, in terms of the number of observations dropped, are for men who did not seem to be working regularly in the pre-retirement years and men for whom the survey was not able to collect employer pension information in the last full-time job. For the former individuals, the concept of retirement is ambiguous if the individual does not seem to be regularly in the labor force. For the individuals without pension information, we are potentially lacking some very important information about retirement incentives, since pensions frequently provide strong inducements to retire at specific dates.

The model has 8 parameters to be estimated. These include the consumption parameter

${ }^{7}$ The Health and Retirement Study is supported principally by a grant from the National Institute on Aging to the Institute for Social Research at the University of Michigan. Additional support is provided by the Social Security Administration and other federal agencies. 
$\alpha$, four elements of $\beta$ including the constant and coefficients for age, poor health, and birth year, two elements of $\delta$ including a constant and a coefficient of age, and the standard deviation of retirement preferences given by $\sigma_{\epsilon}$. The model is estimated using the generalized method of simulated moments. ${ }^{8}$ This method essentially chooses the parameters so as to minimize the differences between a set of observed statistics (moments) in the sample and the values of those statistics that would be implied by the model. In the minimization, the moments are weighted so as to provide the most precise estimates possible with the data.

The estimation uses 46 moments, including the fraction of the sample working full time and the fraction fully retired at various ages. Additional moments are calculated at various ages for specific groups in the sample, including early and late birth cohorts, high and low lifetime earners, and those with poor health. Only the retirement and work decisions as of the survey dates are used in the estimates, thus avoiding the issue of having to interpolate and extrapolate the exact ages of retirement changes between the surveys.

The results of the estimation are given in Table 2. All of the estimated parameters are significant with the exception of the coefficient of the birth cohort variable. Perhaps the most important parameter in these estimates is $\beta_{\mathrm{a}}$, the coefficient of the age variable. If this parameter is relatively high, the value of leisure is increasing rapidly as individuals grow older, and there is only a limited ability for economic incentives to have much of an effect on the retirement age. If, on the other hand, the parameter is relatively low, as it is here, economic incentives such as those contained in social security and pension rules have a much greater scope to change retirement behavior. Another important statistic in the estimation is the q-statistic. If

${ }^{8}$ For a description, See Greene (2000). 
the model is correct, the q-statistic comes from a $\chi^{2}$ distribution with the degrees of freedom given by the number of moments minus the number of parameters. In the present model, this translates into a $\chi^{2}$ distribution with 38 degrees of freedom (46 moments less 8 parameters), which has a $95 \%$ confidence bound of approximately 53.4. The estimated q-statistic of 46.9 is well below this bound, indicating that there is nothing in the data that is inconsistent with the model, at least using these moments.

The estimation also calculates a value of $\rho_{\mathrm{i}}$, the time preference rate, for each individual in the sample. The values of $\rho_{\mathrm{i}}$ are calculated so that for the parameter values given in Table 2 , the assets that are calculated from the model for each individual are equal to the assets (including financial, real estate, and business assets) actually observed in 1992. The resulting distribution of $\rho$ implies a wide variation in the rates of time preference for different individuals. For about 40 percent of the individuals, the time preference rate lies in the range $0-5 \%$, which is roughly equal to the real interest rate. These individuals tend to have high assets relative to their income in order to finance their retirement. At the other end of the spectrum, 27 percent have implied time preference rates of over $50 \%$ per year, which usually means that they have accumulated almost no assets with which to finance retirement. When they retire, their consumption will effectively be limited to their social security and pension benefits.

\section{The Simulation Procedure and the Base Simulations}

The simulation procedure is straightforward. For each individual in the sample, 10,000 sets of values for the leisure preference $\epsilon$ and the partial retirement utility $\mathrm{V}_{\mathrm{p}}$ are drawn. Both of these values are treated as random effects whose values are drawn from the distributions characterized by $\sigma_{\epsilon}, \delta_{\mathrm{o}}$ and $\delta_{\mathrm{a}}$. For each combination of the random effects, the utility value of 
the model is evaluated for each possible age of leaving the full-time job and each possible age of retiring fully. The individual is presumed, given the value of $\epsilon$ and $\mathrm{V}_{\mathrm{p}}$, to chose the two retirement dates so as to maximize utility.

During these evaluations, the actual potential earnings stream for the individual is used, along with the actual pensions, health status, and other explanatory variables for the individual. The time preference rate used in the simulations is assumed to be the rate calculated during the estimation. In other words, the time preference rate is taken as a fixed effect. The fraction of times that the individual retires at various ages is calculated over the 10,000 simulations for the individual, and the results for all the individuals in the sample are aggregated to produce sample frequencies for retirement at various ages. It should be noted that this is also the same procedure that is used during the estimation to give the simulated moments implied by the model. For this reason, the estimation procedure may be called the generalized method of simulated moments.

Figure 1 shows how the retirements simulated for the model compare to the actual retirements for the sample. More properly, the retirements for the sample should probably be called pseudo-retirements, since they are the differences between the percent retired from fulltime work at one age and the percent retired from full-time work the year before. Note that the solid line, which represents the actual retirements from the sample, has a main peak at 62 and a secondary peak at age 65. These two ages are, coincidentally, the early entitlement age and the age of normal retirement in the social security system.

The simulated retirement ages, shown by the dashed line in Figure 1, reproduce these peaks of retirement activity reasonably well. It is important to emphasize that the model generates these peaks without introducing age dummies or splines into the utility function which 
would induce a peak in retirement activity at these ages. This is in marked contrast to other models, which generally have had trouble generating both peaks without using age dummies in the utility function. The peak at age 65 is in response to the reduced actuarial adjustments as individuals reach the normal retirement age and become subject to the delayed retirement credit rather than the more actuarially generous early retirement penalty. For the peak at age 62, the first thing that is likely to come to mind is that individuals with high time preference rates and no savings need to wait until this age in order to have enough resources to support retirement, and to some extent this is true. However, this argument is somewhat muted by the fact that many such individuals have working spouses and/or pensions that could provide some support even if the individual retires before 62. A perhaps more universal explanation is that for individuals with a high discount rate, the fact that benefits must be given up in order to continue working looks like a tax on earnings, and retirement may occur disproportionately after a reduction in net compensation.

Figure 2 indicates the percent who are retired from full-time work and the percent who are completely retired by age. This figure provides a reference point for interpreting the results in the next section. For instance, suppose that a particular policy were to increase the percent retired from full-time jobs at age 64 by 3 percentage points. The percent still working at fulltime jobs at age 64 is only about 35 percent, so such a policy would reduce the number of individuals working at age 64 by almost 10 percent ( 3 percentage points vs. 35 percentage points). One point from this diagram is that half of retirements from full-time work occur between ages 58 and 65, so this is the age range whose retirement is most likely to be affected by any changes in social security. A second point is that partial retirement steadily increases with 
age, especially when compared to full-time workers. At age 58, the group of partially retired workers is only about 10 percent as large as the pool of full-time workers, but by age 67 it exceeds the number of full-time workers by 40 percent.

Since many of the most significant aspects of the Commission's proposals will take effect many years in the future, we would like to examine the effects of these changes, holding other factors constant. To do this, we in effect move the Health and Retirement Study cohorts into the future and do the simulations on these transplanted cohorts. For instance, consider the situation in the years around 2050. Compared to the median cohort in the HRS, which turned 62 in 1998, the cohort that turns 62 in 2050 would have an additional 52 years of real wage growth. Therefore, our procedure is to take all the real earnings and pension amounts of the individuals in the HRS and to increase them by 52 years' worth of real wage growth, assumed to be 1 percent per year. ${ }^{9}$ Dates such as the year of birth are also set ahead by 52 years. ${ }^{10}$

Figure 3 indicates the results of these simulations. As a result of rising real wages, at age 62 retirement from full-time work would grow by over 2 percentage points by 2025, about 5 percentage points by 2050, and by over 8 percentage points by 2075, which is near the last year of the current social security projections. This means that the fraction of individuals working

${ }^{9}$ Source: The 2001 Annual Report of the Board of Trustees (2001, p. 82).

${ }^{10}$ Note that we do not model other demographic changes that would characterize future compared to current cohorts. Nor are other economic changes modeled. This implicitly assumes that the structure of pensions relative to wages would remain the same, and similarly for the distribution of jobs and distribution of spouse employment. By holding these other factors constant, we isolate the effects only of changes in the level of benefits, or of other features of the benefit structure proposed by the President's Commission. We do, however, assume that future cohorts will have lower mortality, consistent with the actuarial assumptions used by the Social Security Administration. 
full-time at age 62 would shrink by almost 15 percent by the end of this period. Note that this increase in retirement is not coming from the cohort coefficient in the estimated utility function. In fact the estimated coefficient is negative, which would go in the wrong direction, although the magnitude of this coefficient is very small. Rather, the increase in retirement appears to be due to the rising real incomes, which by 2075 would have more than doubled. Though substantial, this increase in retirement does not seem to be unreasonably large. As a comparison, Costa (1998; Appendix Table 2A) finds that the labor force participation rate of men age 55 to 64 fell from 91.1 percent in 1910 to 67.0 percent in 1990.

The same pattern, though on a slightly reduced scale, appears for retirement at age 60 . At ages 65 and 67, however, the pattern is considerably different, thanks in large part to changes in the social security rules that have already been legislated and are included in the simulations. At age 65, the cohorts in the HRS are generally subject to the delayed retirement credit, which for them is actuarially unfair and discourages work. By 2025, the normal retirement age will have increased to age 67 , so that individuals at age 65 will be subject to the early retirement reduction, which is actuarially more fair and would encourage more work. This means that in 2025, full time work at age 65 should increase despite the higher lifetime incomes. After 2025, however, retirement gradually increases by about 5 percentage points between 2025 and 2075, which is about the same amount as at age 62. For individuals at age 67, a similar pattern emerges. This age group is always after the normal retirement age, even in 2025. However, the abolition of the earnings test after normal retirement age means that at that time the current disincentives to work will be gone. The simulations suggest that the resulting increase in work should approximately offset the increases in retirement arising from the higher lifetime income 
levels. Again, after 2025 the increasing incomes result in a gradual increase in retirement from full time work.

\section{Simulations of the Commission's Proposals}

In this section we will look at the retirement effects on married males of the various elements in the two major proposals of the President's Commission to Strengthen Social Security. The elements we will look at are those listed in Table 1, including the personal accounts, changes in the overall level of benefits, changes in the actuarial adjustments, special adjustments for low wage workers, changes in the calculations of survivor benefits, and reductions in the marginal replacement rate for those in the highest income bracket of the primary insurance amount formula.

The most visible aspect of the proposals is to establish the personal accounts. The contributions to the accounts are relatively clear. Under model 2, individuals would contribute $4 \%$ of covered earnings up to $\$ 1,000$, while under model 3 , they would contribute $2.5 \%$. These amounts would be carved out of the existing social security taxes. Model 3 would require an additional 1\% contribution, without any dollar limits, beyond existing taxes. Under these rules, contributions would stop at earnings of $\$ 20,000$ because of the cap, and beyond about $\$ 28,000$ contributions to model 3 would be higher. Overall, total contributions to model 3 would be expected to be higher, primarily because the additional $1 \%$ contributions do not have a cap. The fact that model 3 has a higher interest rate on the offset account, $2.5 \%$ vs. $2 \%$, to some extent offsets the higher overall contribution rate in model 3.

The procedure to withdraw funds from the personal accounts, however, is not very clear. The actuary assumes that withdrawals are converted to a joint and two-thirds variable annuity 
when the individual retires. The problem, however, is retirement is not a very well defined concept. It is elusive enough, in fact, that the current (or traditional) system does not use the concept. Instead it relies on the earnings test. If an individual eligible for benefits is found working and earning more than a certain amount, the benefits are reduced $\$ 1$ for every $\$ 2$ in benefits beyond the earnings test amount, until benefits are exhausted. The lost benefits are later restored in a more or less actuarially fair manner, but this may be overlooked by an individual with a relatively high time preference rate. Given the elusiveness of the concept of retirement, it is not completely clear exactly how the withdrawal of funds from the personal accounts will be implemented.

In this paper, we will look at two possibilities. One possibility essentially mimics the earnings test. It assumes that once an individual reaches age 62, the account is converted to a joint and two thirds variable annuity. This annuity amount is added to the traditional benefit, and the combined benefit is subjected to the earnings test. For every $\$ 2$ that the benefits are above the earnings test amount, $\$ 1$ in benefits is lost. The lost benefits are allocated to traditional benefits and the annuity proportional to the full amount of each type of benefit. For the part of the traditional benefits that are lost, the usual rules for early reduction factors apply. For the part of the annuity that is lost, that amount is converted to an annuity the next year and added to the original annuity. For example, suppose that the annuity at age 62 is $\$ 5,000$, and half of it is lost. The lost 2,500 is converted to an annuity at age 63, with an annual amount of perhaps $\$ 125$. This would mean that the total annuity at age 63 would be the original $\$ 5,000$ plus $\$ 125$, or $\$ 5,125$. The other possibility we will look at in terms of the withdrawals from the personal accounts is that individuals can convert the balances to a joint and two-thirds variable annuity, 
and the earnings test does not apply.

In both cases, we assume that the personal accounts grow at a $4.6 \%$ real return, which the social security actuaries calculate is the average return of a portfolio of $50 \%$ stock and $50 \%$ bonds. Figure 4 indicates the effects of the personal annuities on retirement at age 62. In each case, it is assumed that personal annuities are available for the entire working lives of individuals, which is a slight overstatement for individuals reaching age 62 in 2025 . In each group, the first two bars reflect the retirement effects of the models 2 and 3, assuming that the joint benefits will be subject to the earnings test. The last two bars in each group assume that only the traditional benefits are subject to the earnings test. In both cases, the personal benefits have a somewhat greater effect in model 3, probably because the amounts are higher. Also, the effects are slightly higher when the earnings test is applied only to the traditional benefits. Overall, it appears that the personal accounts of the size that the Commission contemplates would raise the percentage of 62-year olds who are retired by between 1.5 and 2.5 percentage points.

Other than the personal accounts, one of the strongest changes in the proposals is to reduce the overall level of traditional benefits relative to the benefits provided under the current formula. Figure 5 provides the results of simulations examining the effects of this change. In addition to the changes in the two proposals, the figure also simulates changes to the legislated benefits which would occur were there no other changes in the current system, so that benefits would be lowered to match revenues when the trust fund is exhausted. These are labeled as feasible benefits.

For each year in the figure, the left bar analyzes the effect that would occur if benefits are 
limited to the feasible amount under current law. Benefits would hardly be affected in 2025, since under current projections the system would still be solvent and able to pay benefits under the current formula. Between 2025 and 2050, however, the trust fund would be exhausted, and only about three-quarters of the currently legislated benefits could be paid. By 2075, the percentage of benefits that could be paid is expected to drop further to about two-thirds. The reductions in benefits make retirement less attractive, particularly for individuals with high time preference rates. The effective reduction in compensation at age 62 from reducing benefits is decreased for these individuals, reducing incentives to retire. By 2075 the effect of benefit level changes on the percent retired amounts to over 4 percentage points at age 62, which means the full-time work by 62 year-olds would increase almost 10 percent relative to what it would otherwise be.

The second bar in each group of figures looks at the effect of holding the overall level of benefits constant in real terms, which is the proposal in the Commission's reform model 2. Note that although benefits are constant in real terms, they are a shrinking fraction of real wages. As a result, by 2075 the replacement rate of traditional social security benefits would be less than half of the current levels. The retirement effect would grow steadily over time until, by 2075, it would reduce retirement from full-time jobs by around 7 percentage points, which amounts to an increase in full-time workers of around 19 percent compared to current law, or about 2.5 percentage points compared to the feasible alternative. The third bar in each group examines indexing benefits to life expectancy, which is projected to allow real benefits to grow by about half the rate that would occur under the current formula. This is the proposal in the Commission's reform model 3. Not surprisingly, the effects are roughly half of the effects of the 
proposal to hold real benefits constant. Perhaps more surprisingly, the effects are roughly comparable to allowing social security to run its course and, when the trust fund runs out, to pay benefits proportional to the revenues of the system year-by-year.

The information in Figure 5 pertains to retirement from full-time work at age 62. The effects at other ages are much as would be expected. Below age 62, before social security benefits are available, the effects of these changes are much reduced, though not completely trivial. After 62, the effects continue at very gradually diminishing levels as a percentage of individuals at those ages. The diminution of the effects for older workers is undoubtedly due to the fact that more and more of them are already retired and beyond the margin of considering whether to delay retirement. Relative to the number of individuals still in full-time jobs, however, the effects at age 65 are greater than those at age 62. For instance, for those age 62, the inflation indexing proposal would increase full time work in 2075 from 37.1 percent of the cohort to 44.1 percent, an increase of 7.0 percentage points, or 19 percent of the individuals still working. At age 65, the corresponding percentages are 22.5 percent and 27.9 percent, which is an increase of 5.4 percentage points but 24 percent of those still working in full-time jobs. The net implication of these results is that these changes in the overall benefit levels would be expected to have a substantial effect at all ages after social security benefits are available.

Similar results are obtained when we examine the effects of the various indexing schemes on full retirement at age 62 (not shown). The magnitudes and patterns evident in Figure 5 are reproduced with only small variation. This means that the changes in the overall level of benefits is not merely shifting individuals from partial retirement to full-time work. Rather, they are having the similar effects on both full-time work and work of any kind, with the implication 
that the number of individuals in part-time work is not tremendously affected.

Figure 6 looks at the proposal to increase the penalties for early retirement. By reducing the benefit at the early retirement age and increasing the reward to continued work through normal retirement, incentives to work increase from the early retirement age until the normal retirement age. The retirement effects after normal retirement age are more complex. The model is designed so that the increase the financial rewards for continued work past the normal retirement age depends on benefit claiming, a financial decision, but not on labor market activity. Because the earnings test has been abolished for those over the normal retirement age, those with a high time preference rate will no longer face an opportunity cost of not claiming benefits when deciding how long to work past normal retirement age. They simply can claim benefits as soon as they reach normal retirement age, and make their employment decision independently. ${ }^{11}$ These proposals are part of the Commission's reform model 3, but are not part of reform model 2. They were included explicitly to provide incentives for individuals to work longer, which presumably helps the financial situation of the trust fund. The figure considers the effects of these provisions for various ages at various points in time. Although the changes do not apply to the cohorts of the Health and Retirement Study, who would have by and large already retired by the time these proposals would take effect, the first bar of each group indicates what would have happened had they been subject to these adjustments.

Figure 6 shows substantial effects for these changes, particularly for those 65 years old. The changes are measured as percentage points of the number of individuals at the given age.

\footnotetext{
${ }^{11}$ The model assumes that anyone who is retired, or that those who are beyond the normal retirement age, will claim their benefits immediately.
} 
The percentage changes in those working full-time is considerably larger than the percentage point changes. For instance, the 3.4 percentage point increase in full-time work for 65 year olds in 2075 represents a 15 percent increase in the number of 65 year olds working full-time in that year. The changes are in the desired direction and not inconsequential. The change for the current cohorts at age 65 is the largest in magnitude, probably because 65 was the normal retirement age for those cohorts, and delayed retirement credits averaging around 6 percent was relatively low. A similar situation obtains for the current cohorts at age 67. Future cohorts would just have reached the normal retirement age at 67 , so the effects at that age for those cohorts would be much lower.

Just focusing on future cohorts, however, the effects at age 62 and 65 are still considerable. Between three and four percentage points of the entire cohort would be added to the full-time employment rolls at these two ages, and at the ages in between as well. There is some tendency for the effect to decline for the later cohorts, particularly at age 65. This is probably due to the fact that the number of individuals in full-time work at that age will be gradually diminishing, as indicated in Figure 3.

Figure 7 turns attention to the Commission's proposals to offset the effects of the proposed changes on the lowest earners. The Commission's proposals in their reform model 2 differ somewhat from the proposals in reform model 3. Both reform models focus on longerterm workers and do not propose any changes for workers with less than 20 years of coverage. The changes for workers with between 20 and 30 years of coverage are phased in. The provision would boost benefits by 40 percent for minimum wage workers with 30 years of coverage under reform model 2, and by 12 percent under reform model 3. For workers with more than 30 years 
experience and/or less than the minimum wage, the percentage could be higher than 12 percent in reform model 3, but not above 40 percent in reform model 2. In these calculations, the minimum wage is presumed to grow at roughly the same rate as overall wages.

Figure 7 suggests that the effects of either of these provisions on overall full-time work effort would be considerably lower than for either of the other two changes that have been considered. The proposals would increase retirement, presumably because they would make retirement more affordable for low wage workers, and the higher benefits would also increase the penalty for continued work for those with high time preference rates. Nevertheless, neither of these proposals would change retirement at age 62 by more than a percentage point of the cohort size, considerably less than the several percentage point change for the previous proposals. The effect of the proposal in reform model 2 is somewhat greater than that for reform model 3, reflective of the fact that the benefit increases are larger in reform model 2.

Figure 8 looks at the effects of the low wage provisions on the group of respondents who would be affected by the provisions. Among this group, the retirement effects are considerably larger for reform model 2, reaching an increase of almost 3 percentage points in the number of such individuals retired from full-time work. A primary reason for the larger increase in the effect among the affected workers in reform model 2 is that the percentage of affected workers is considerably less under reform model 2 than under reform model 3. The increased benefits for low wage workers under reform model 2 phase out at twice the minimum wage, and only about 18.8 percent of the sample is under this limit in the HRS. The increased benefits under reform model 3 phase out at the average earnings amount, which means that a considerably larger percentage (38.4 percent) of the sample is affected. The smaller percentage under reform model 
2 means that the dilution of the effect in the overall sample averages is greater than for reform model 3.

The next figure looks at the retirement effect of increasing the survivor benefit to 75 percent of the amount that the couple would have received had both spouses survived. This benefit increase is limited to the average primary insurance amount of all worker beneficiaries in the previous year, reduced appropriately if the worker started taking any benefits before the normal retirement age. Possibly because its effects are not felt until around 20 years after retirement, the changes in the retirement probabilities are much smaller for this element of the proposals than they have been for the previous elements. For the overall population, the increases in retirement from full-time work at age 62 would be less than 0.3 percent for the current generation, and around 0.1 percent for the generations approaching retirement around 2025 and afterward. Since around a third of the respondents are eligible for this benefit, the increases for those affected are roughly three times as large. The larger effect for the current generation relative to future generations appears connected to the fact that the future generations will be subject to a later normal retirement age than was the case for the original HRS generation. In any case, retirement effect of increasing survivor benefits appears to be quite modest, especially when compared to the other changes being considered.

The final figure examines the effects of lowering the top bracket in the PIA formula to 10 percent from its current level of 15 percent. The effects of this proposal are again fairly modest, although the effects in this case are roughly the same regardless of which generation is considered. For all generations, the proposal would increase retirement from full-time work at age 62 by about a quarter of a percentage point. Since not quite two-fifths of the sample would 
be affected by this change, the effects on the part of the sample affected by the change are about two and a half times the effect on the entire sample.

The relatively small size of changing the upper range of the PIA formula probably results from the relatively small size of the benefit changes which would occur as a consequence. In 2000, the upper bend of the PIA formula occurred at $\$ 1,332$. Looking at men who started claiming benefits in that year, approximately 38 percent of them had PIA's above this amount. ${ }^{12}$ The median PIA of those whose AIME was over the upper bend point appears to be between $\$ 1,450$ and $\$ 1,500$ per month. Reducing the percentage applicable above the upper bend point from 15 percent to 10 percent would lower benefits by around $\$ 50$, or about 3 percent. Thus, benefits calculated for earnings above the upper bend point constitute only a small fraction of total benefits even for individuals above the upper bend point. As a result, it is not surprising that this change would have only a relatively small effect on retirement.

In all of these exercises, we have not considered the retirement impact of the changes in taxes that would necessary to finance them. According to the Actuaries' Supplement, these costs would range from 2.07 percent of the long-term taxable payroll for the proposal to index benefits to inflation to 0.08 percent of the long-term taxable payroll for the proposals to increase benefits for lower-income surviving spouses. From the participants' point of view, the tax changes would mainly be a wealth effect, much like the general increase in earnings over time. From the base simulations, we saw that increasing general incomes by over 100 percent would affect retirement at age 62 by only about 7 percentage points. Thus, the retirement effects of the taxes

${ }^{12}$ Annual Statistical Supplement, 2001, Table 6.B4. This figure approximately agrees with the percentage calculated from the HRS. 
necessary to finance these changes would be tiny, implying that the changes we are finding arise from the changes in retirement incentives. As an example, it is clear that the present system is largely responsible for the retirement peaks at ages 62 and 65. If a proposal such as inflation indexing benefits were to cut traditional benefits by a half over 75 years, the incentives to retire at these ages would also be reduced by a corresponding amount.

In summary, some of the elements of the Commission's proposals would have large consequences for retirement, and others would have only minor consequences. Table 3 indicates the effects of the various elements of the proposals for the retirement from full-time work for a 62 year old individual around 2075. The first line corresponds to the trend toward earlier retirement that would occur if no changes were made. The remaining lines summarize the effects of the various elements of the proposals, some positive and some negative. The first column corresponds to Model 2 of the commission, and the second column corresponds to Model 3.

In both sets of proposals, the net effect of the proposals is to reduce retirement at age 62 by about 4 percentage points. Thus, these proposals will offset about half of the trend toward earlier retirement that overall rising incomes is likely to engender over the next 75 years. In Model 2, the most powerful effect by far is the change to inflation indexing of benefits. This effect alone would reduce retirement by 7 percentage points. In Model 3, an effect of the same magnitude is split between the more moderate longevity indexing (4 percentage points) and the increases in the actuarial rewards to continued work (3.2 percentage points). Note that Model 2 does not include the changes in the actuarial rewards. The personal accounts offset these effects to a limited extent, about 1.5 to 2.5 percentage points. The other elements of the proposals, 
including increasing benefits for low-wage workers, reducing benefits to high-wage workers, and increasing survivor benefits for workers below the median wage, would produce only very modest changes in retirement behavior.

\section{Conclusions}

The model used in this paper has proven adept at explaining current patterns of retirement behavior. By including heterogeneous time preferences and heterogenous retirement preferences, the model is able to capture the peaks in retirement behavior at age 62 and age 65 without incorporating discontinuities in preferences which would make individuals want to retire preferentially at those ages. The model is also able to approximate the rest of the retirement distribution fairly accurately, and to include the non-trivial number of individuals who go through a phase of partial retirement as well. In short, the model contains the essential elements that permit it to analyze the effects on retirement of various potential changes which would alter individuals' incentives to retire, including potential changes in the social security system.

Changes in social security are very nearly a certainty, given the approaching retirement of the baby boom. The proposals of the President's Commission to Strengthen Social Security are a prominent example of the potential changes that can be considered. The effects of these proposals on the benefits of various groups and on the financial solvency of the system have been carefully examined by the actuarial office of the system, but the potential retirement effects of these proposals have been less well examined. The analysis presented in this paper suggests that these effects may be substantial. Over the next 75 years, the trend toward less work and earlier retirement, which has recently been interrupted, should continue as rising incomes induce individuals to take a larger percentage of their potential wages as leisure. A couple of the 
Commission's proposals contain features which would work the other way, and would provide individuals with incentives to delay their retirement substantially. The overall effect could offset almost half the trend toward earlier retirement that would otherwise occur. 


\section{References}

Burtless, Gary and Rober Moffitt. 1984. "The Effect of Social Security Benefits on the Labor Supply of the Aged”. In H. Aaron and G. Burtless, editors. Retirement and Economic Behavior. Brookings: Washington, D.C..

Coile, Courtney and Jonathan Gruber. 2000. “Social Security and Retirement”. NBER Working Paper 7830.

Cost, Dora L. 1998. The Evolution of Retirement: An American Economic History, 1880-1990. Chicago: University of Chicago Press.

Fields and Mitchell. 1984. Retirement, Pensions and Social Security. MIT Press.

French, Eric. 2002. “The Effects of Health, Wealth, and Wages on Labor Supply and Retirement Behavior”. Xeroxed. Federal Reserve Bank of Chicago.

Greene, William H. 2000. Econometric Analysis, Fourth Edition. Upper Saddle River: Prentice Hall.

Gordon, Roger H. and Alan S. Blinder. 1980. "Market Wages, Reservation Wages and Retirement". Journal of Public Economics 14: 277-308.

Gustman, Alan L. and Thomas L. Steinmeier. 1985."The 1983 Social Security Reforms and Labor Supply Adjustments of Older Individuals in the Long Run". Journal of Labor Economics, Vol. 3, No. 2 (April, 1985) pp. 237-253.

(May, 1986) pp. 555-584.

. 1986. "A Structural Retirement Model." Econometrica, Vol. 54, No. 3

. 1991. "Changing Social Security Rules For Workers Over 65: Proposed

Policies And Their Effects", Industrial And Labor Relations Review.

. 2001/2002. “Retirement and Wealth”. Social Security Bulletin 64(2): 66-

91.

. 2002a. "The New Social Security Commission Personal Accounts: Where Is the Investment Principal?” NBER Working Paper No. 9045. July, 2002.

. 2002b. "The Social Security Early Entitlement Age In A Structural Model of Retirement and Wealth”. NBER Working Paper 9183. September, 2002.

Paper 9404, December.

2002c. "Retirement and the Stock Market Bubble”. NBER Working 
Forthcoming. " Social Security, Pensions and Retirement Behavior within the Family”. Journal of Applied Econometrics.

Lumsdaine, Robin L. and Olivia S. Mitchell. 1999. "New Developments in the Economic Analysis of Retirement”. In Orley Ashenfelter and David Card, editors. Handbook of Labor Economics. Amsterdam, Holland: 3261-3308.

Panis, Constantijn, Michael Hurd, David Loughran, Julie Zissimopoulos, Steven Haider and Patricia StClair. 2002. “The Effects of Changing Social Security Administration's Early Retirement Age and the Normal Retirement Age.” Santa Monica: RAND.

President's Commission to Strengthen Social Security. 2001. "Strengthening Social Security and Creating Personal Wealth for All Americans”. Washington, D.C.: December. http://www.commtostrengthensocsec.gov/reports/Final_report.pdf

Rust, John and Christoper Phalen. 1997. "How Social Security and Medicare Affect Retirement”. Econometrica 65(4):781-831.

Social Security Administration. 2001. Annual Statistical Supplement 2001, to the Social Security Bulletin. SSA Publication No. 13-11700. Washington, D.C.: U.S. Government Printing Office.

The 2001 Annual Report of the Board of Trustees of the Federal Old-Age and Survivors Insurance and Disability Insurance Trust Funds. 
Table 1

Elements of the Commission Reform Models

\section{Reform Model 2}

\author{
Personal Accounts \\ $4 \%$ contribution up to $\$ 1,000$ \\ $2 \%$ real return of offset accounts
}

Traditional benefits held constant in real terms

Minimum benefit for 30 year minimum wage worker increased to $120 \%$ of poverty level

Increase survivor benefit to $75 \%$

of couple benefit
Reform Model 3

\author{
Personal Accounts \\ $2.5 \%$ contribution up to $\$ 1,000$ \\ $2.5 \%$ real return on offset accounts \\ $1 \%$ additional contribution required \\ Traditional benefits indexed to \\ changes in life expectancy
}

Minimum benefit for 30 year minimum wage worker increased to $100 \%$ of poverty level

Increased penalties for early retirement and increased rewards for delayed retirement

Increase survivor benefit to $75 \%$ of couple benefit

Decrease marginal benefit for highest AIME bracket from $15 \%$ to $10 \%$. 
Table 2

Estimated Results

\begin{tabular}{|c|c|c|c|}
\hline Symbol & Description & $\begin{array}{c}\text { Coefficient } \\
\text { Value }\end{array}$ & t-statistic \\
\hline \multirow[t]{2}{*}{$\alpha$} & Consumption parameter & -0.26 & 8.57 \\
\hline & Parameters in $\beta$ & & \\
\hline$\beta_{0}$ & Constant & -9.85 & 304.21 \\
\hline$\beta_{a}$ & Coefficient of Age $^{\mathrm{a}}$ & 0.076 & 5.21 \\
\hline$\beta_{\mathrm{h}}$ & Coefficient of Health $^{\mathrm{d}}$ & 3.92 & 4.57 \\
\hline \multirow[t]{2}{*}{$\beta_{c}$} & Coefficient of Cohort ${ }^{\mathrm{b}, \mathrm{d}}$ (Year of Birth) & -0.01 & 0.07 \\
\hline & Parameters in $\delta$ & & \\
\hline$\delta_{0}$ & Constant & -1.78 & 3.53 \\
\hline$\delta_{\mathrm{a}}$ & Coefficient of Age $^{\mathrm{c}}$ & 0.46 & 3.10 \\
\hline \multirow[t]{3}{*}{$\sigma_{\epsilon}$} & Standard Deviation of $\epsilon^{\mathrm{d}}$ & 5.79 & 7.44 \\
\hline & q value & \multicolumn{2}{|c|}{46.92} \\
\hline & Number of observations & \multicolumn{2}{|c|}{2305} \\
\hline
\end{tabular}

Several variables are differenced from their approximate means in the sample in order to facilitate estimation. They are:

a The actual variable is age - 62 .

b The actual variable is cohort - 1936 .

c The actual variable is age - 65 .

$d$ These coefficients are all relative to the age coefficient, again to facilitate estimation. See text for explanation. 
Table 3

\section{Effects of Proposed Social Security Changes on Retirement from Full-Time Jobs at age 62 in 2075}

Model 2

General Retirement Trend

Effects of Social Security Changes

Personal Accounts

Changes in Indexation

Changes in Actuarial Adjustments

Provisions for Low-Wage Workers

Changes in Survivor Benefits

Reduction of Top AIME Bracket

Net Effects of Social Security Changes

Overall Change in Retirement
$+8.7$

$+1.8$

$-7.0$

$+0.9$

$+0.1$

-

$-4.2$

$+4.5$
Model 3

$+8.7$

$+2.7$

$-4.0$

$-3.2$

$+0.9$

$+0.1$

$+0.2$ 
Figure 1

Retirements From Full-Time Work

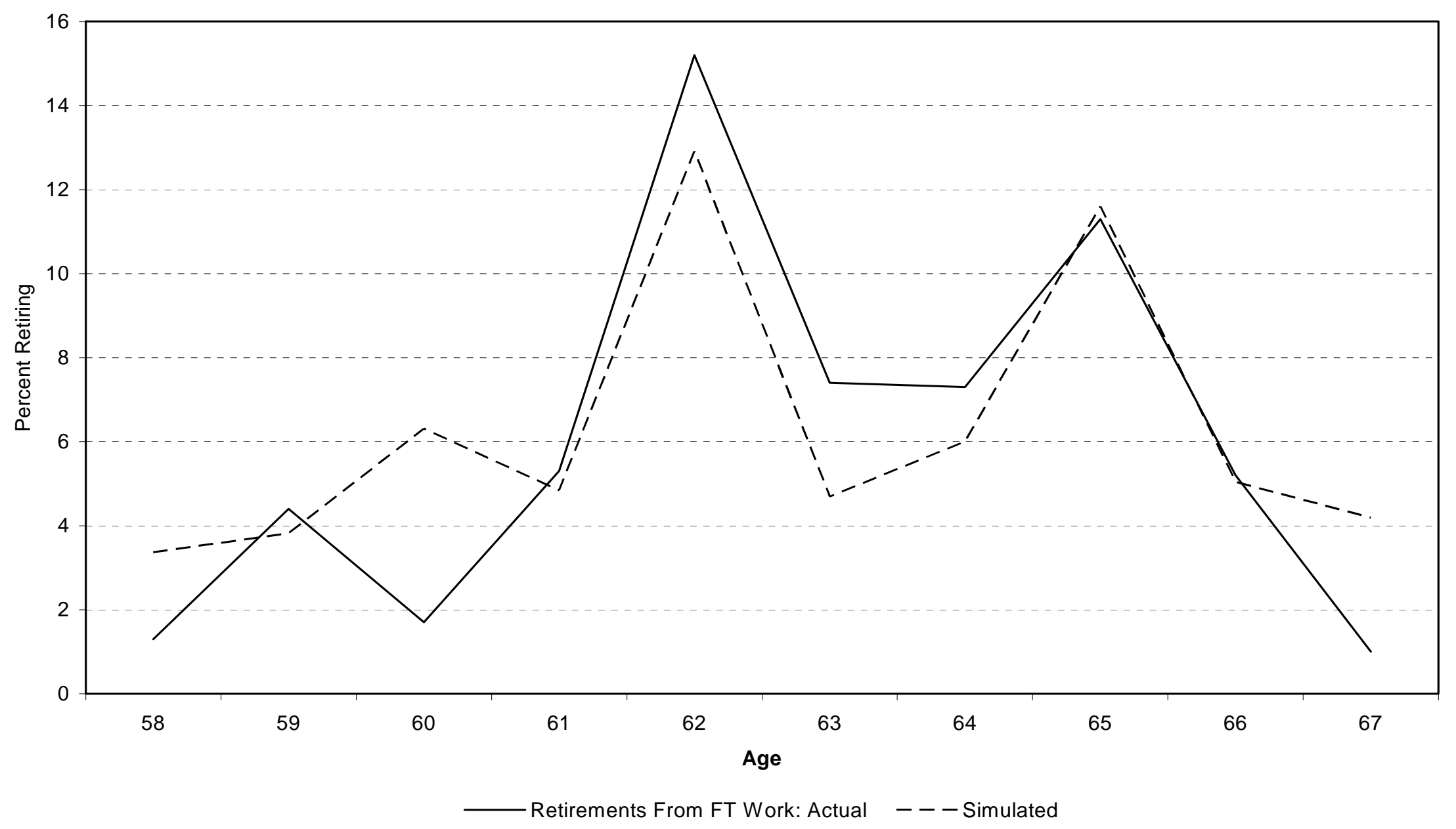


Figure 2

Simulated Percent Retired From Full-Time Work and Percent Fully Retired By Age

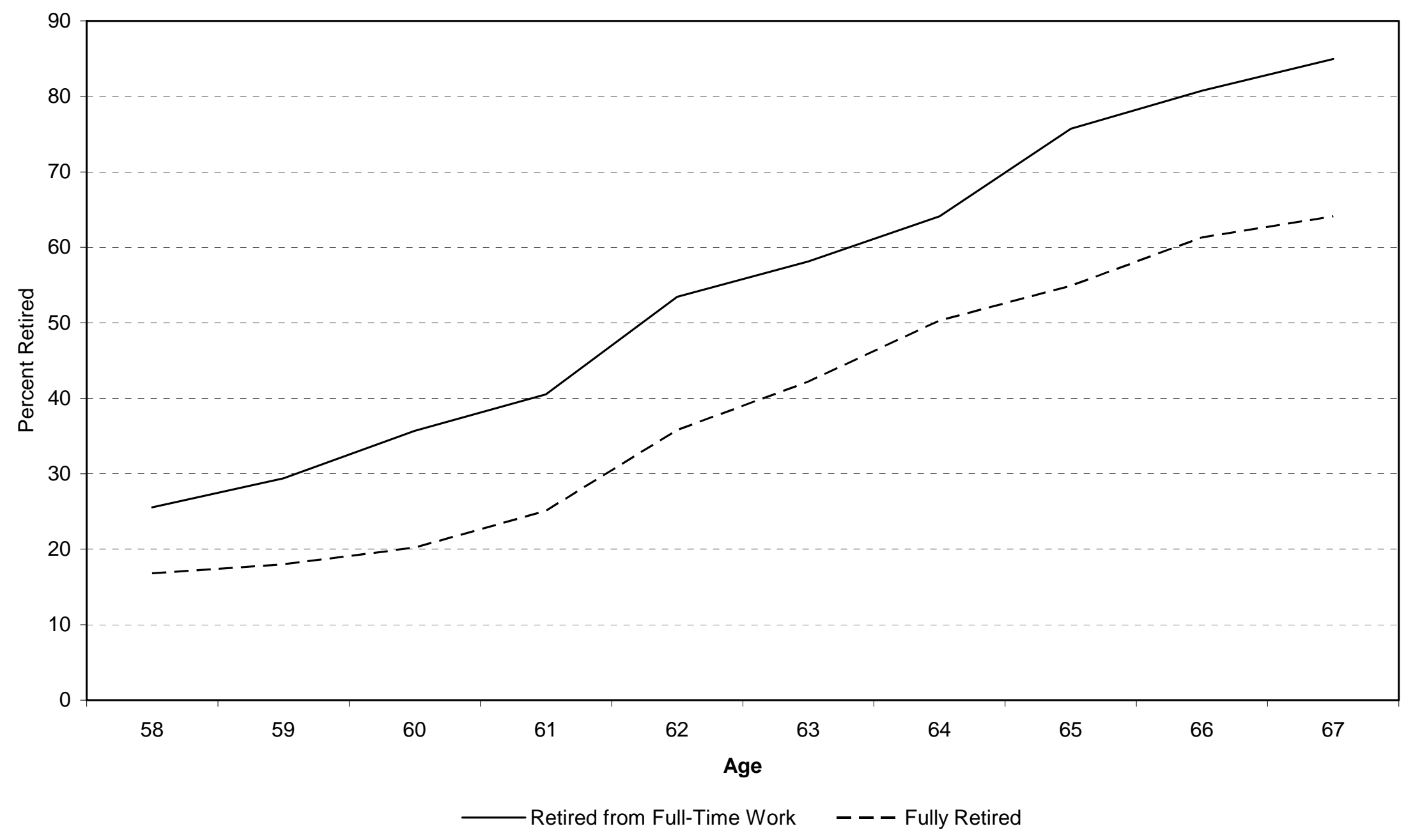


Figure 3

Changes in Percent Retired from Full-Time Work Over Time by Age

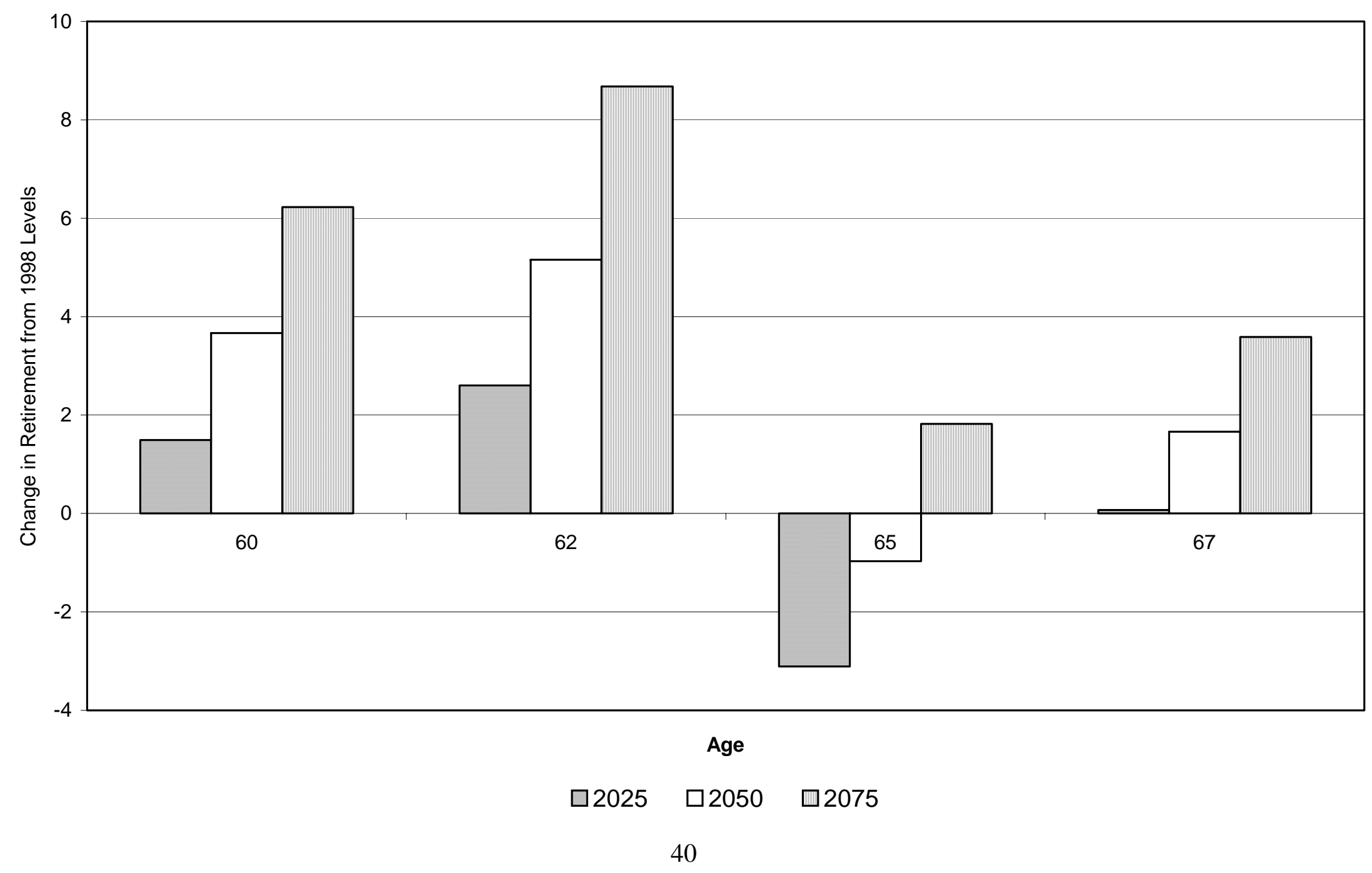


Figure 4

Effects of Personal Accounts On Percent Retired From Full-Time Work at Age 62

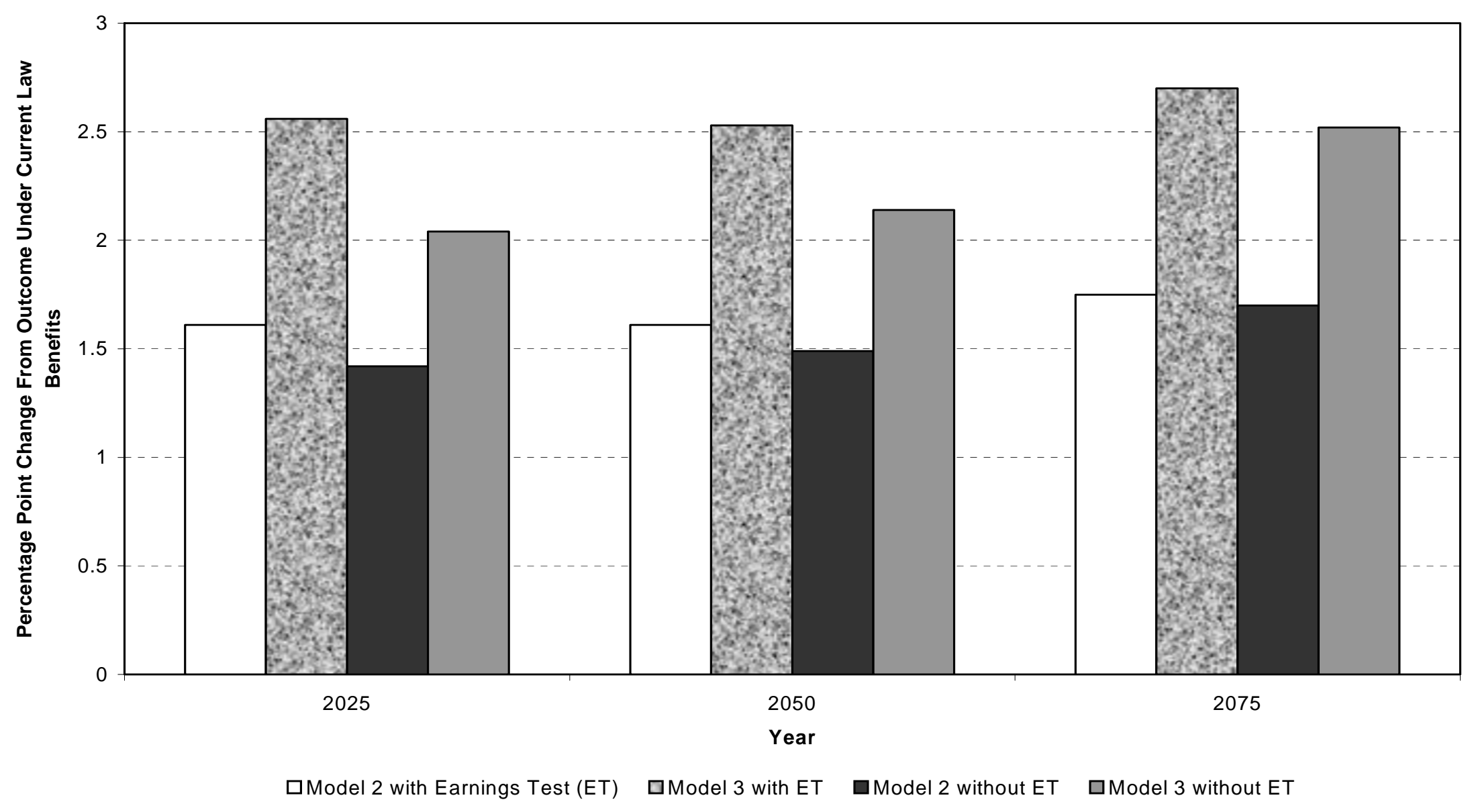


Figure 5

Effects of Adjustments in Benefit Levels On Percent Retired From Full-Time Work at Age 62

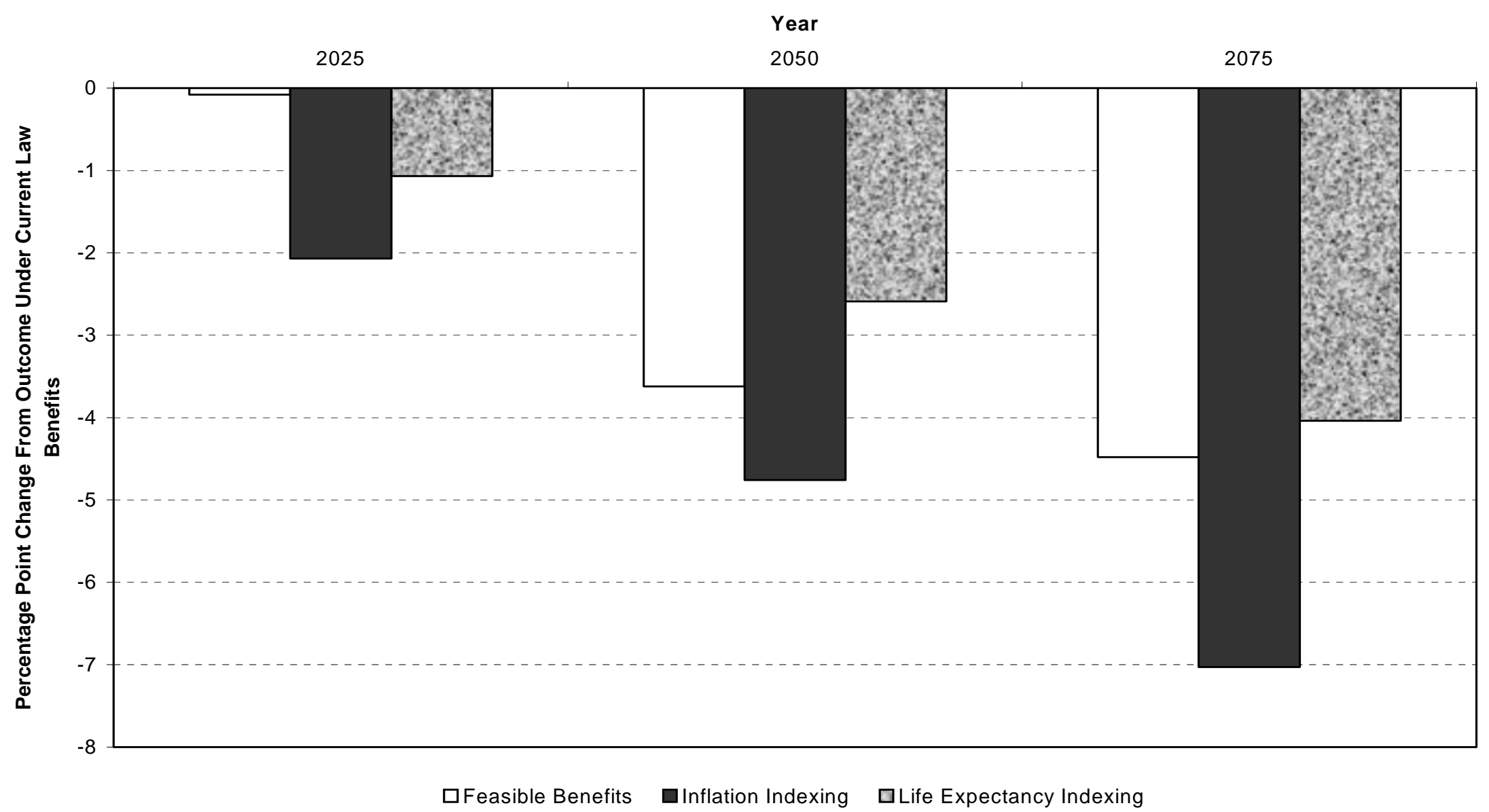


Figure 6

Effects of Changes in Actuarial Adjustments on Percent Retired from Full-Time Work

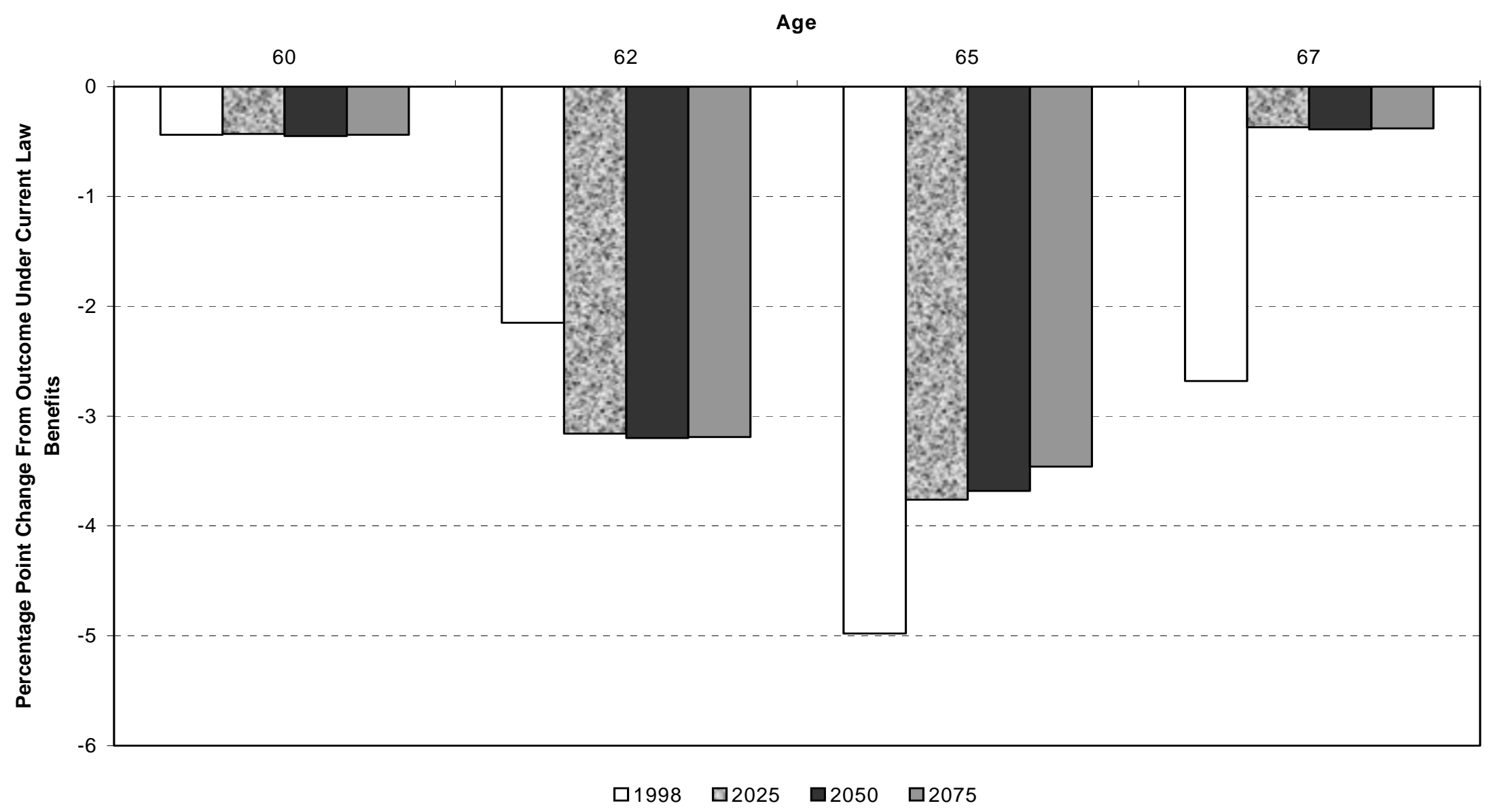


Figure 7

Effects of Low-Wage Provisions on Percent Retired from Full-Time Work at Age 62

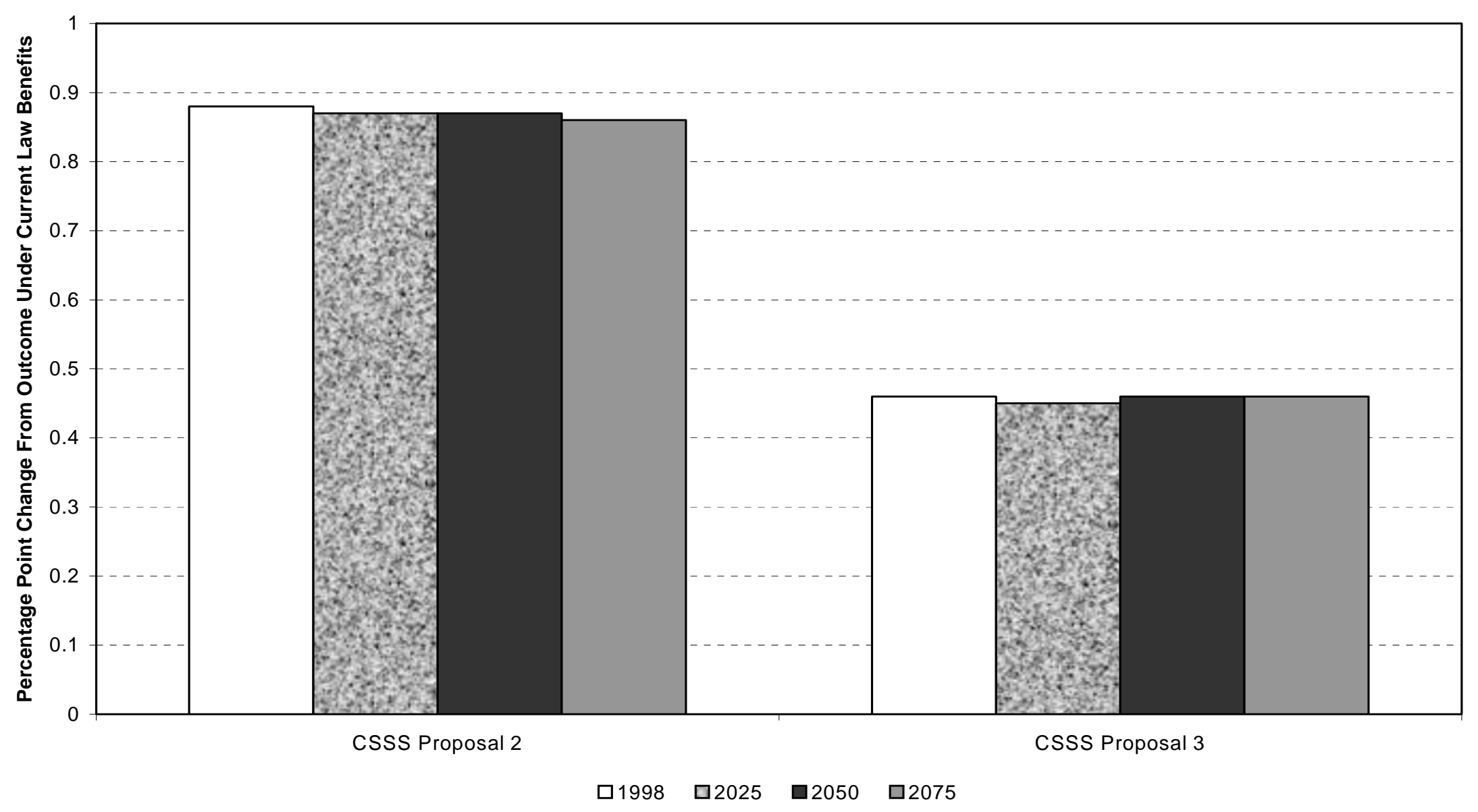


Figure 8

Effects of Low-Wage Provisions on Retirement of Low-Wage Workers

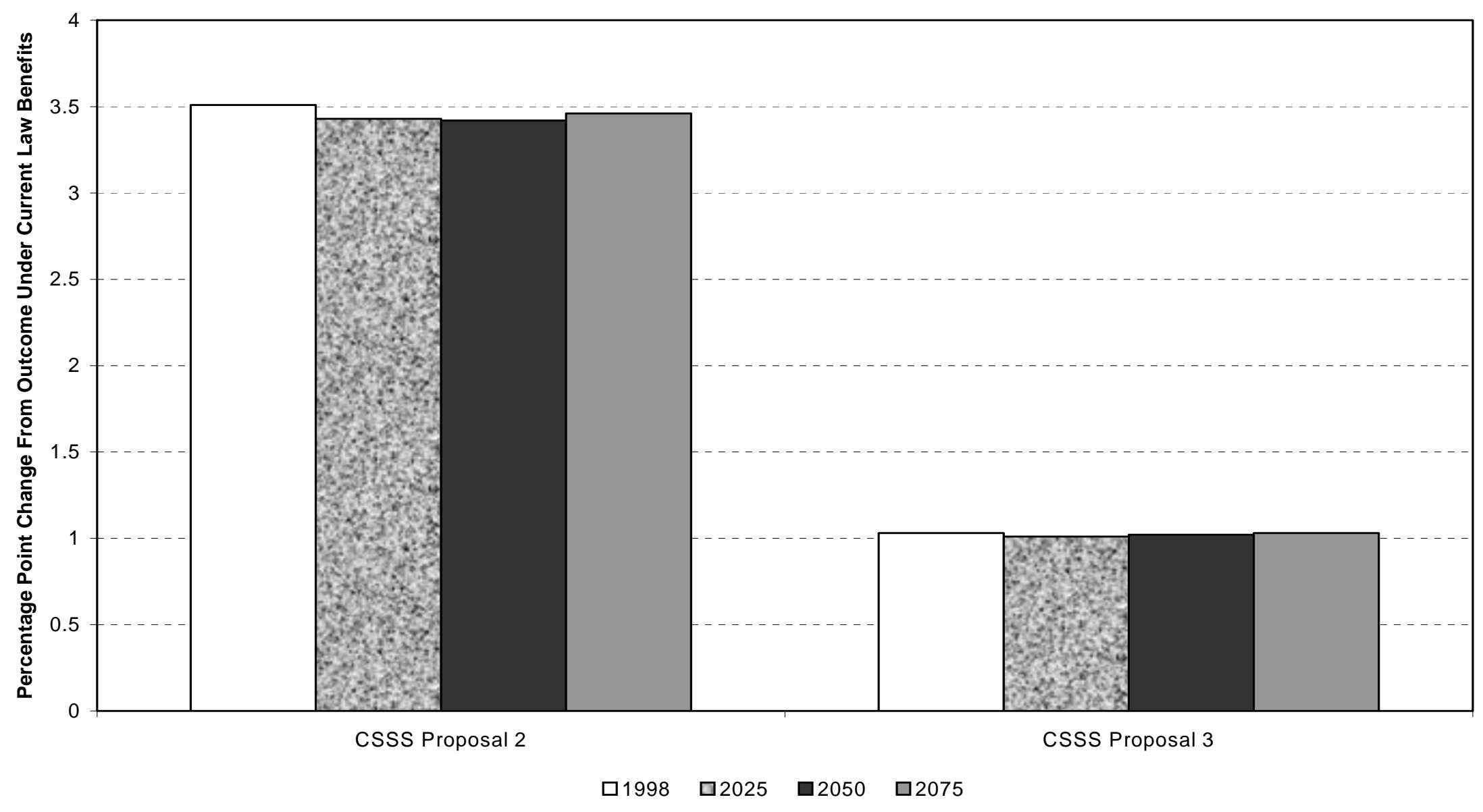


Figure 9

Effects of Survivor Benefit Supplements on Retirement From Full-Time Work at Age 62

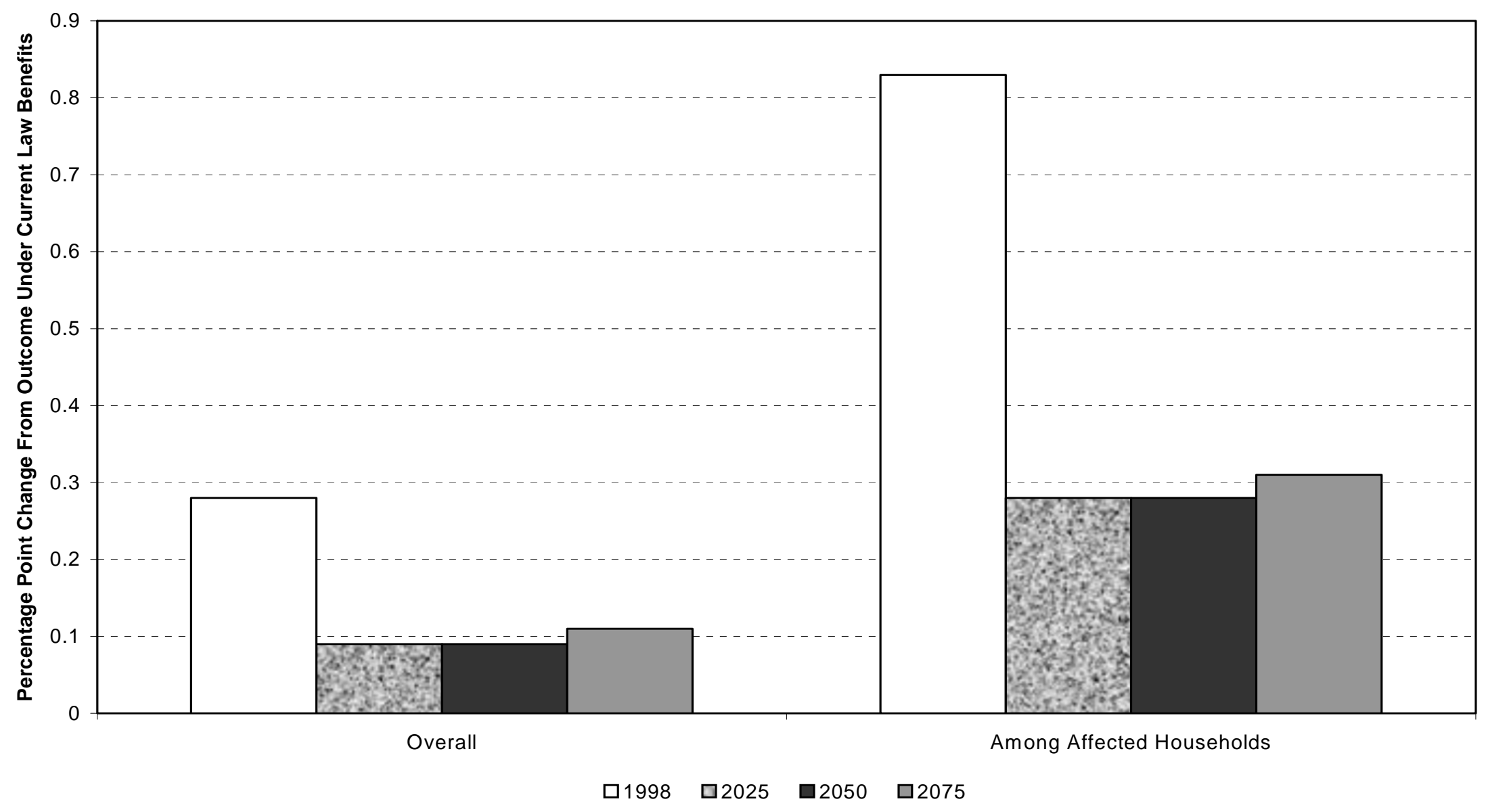


Figure 10

Effects of Top PIA Bracket Reduction on Retirement From Full-Time Work at Age 62

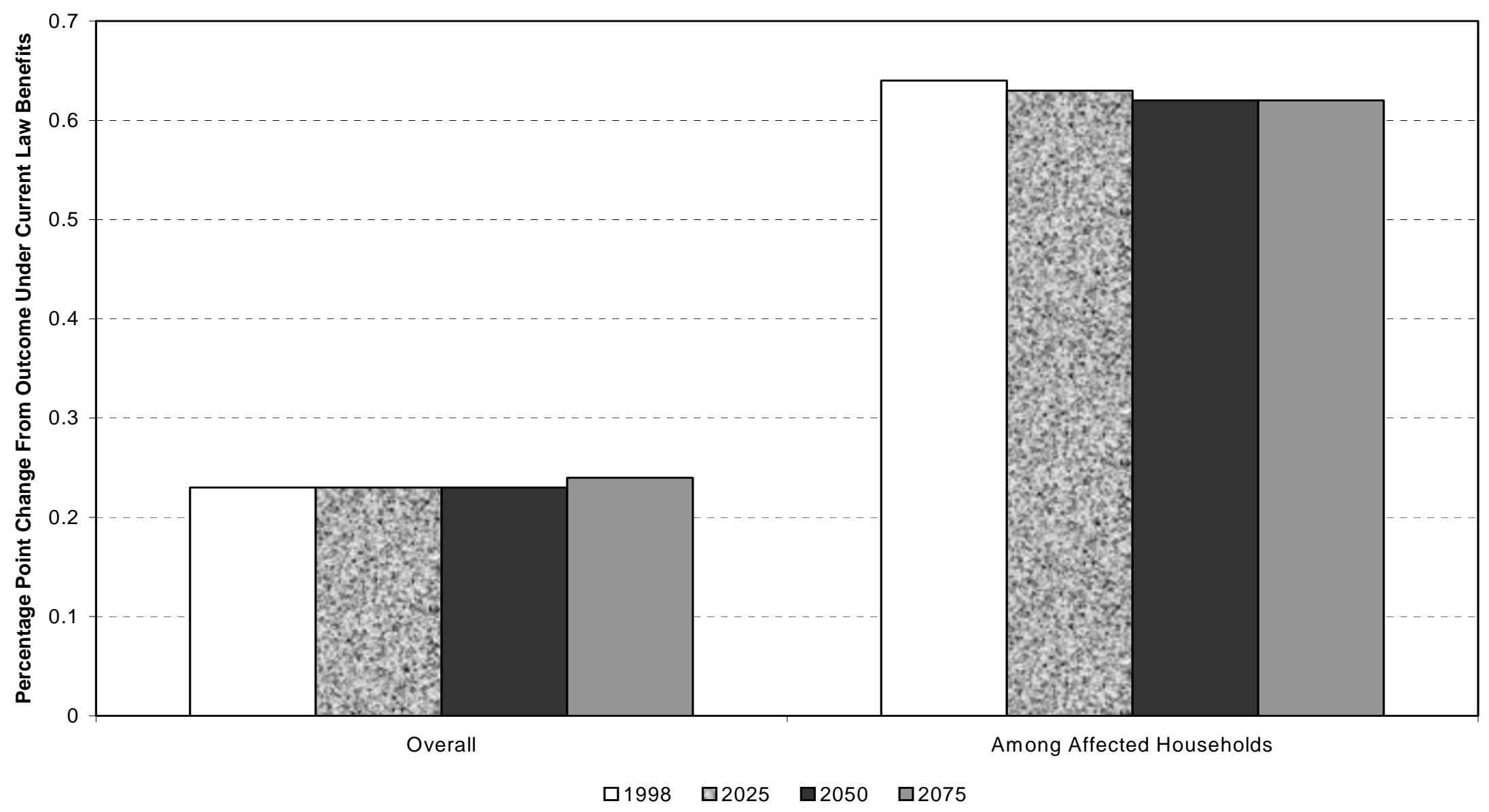

